\title{
GURU MERAH PUTIH: ULAMA BETAWI DALAM PERJUANGAN KEMERDEKAAN (1945-1950)
}

\author{
Humaidi \\ Email : humaidiunj@gmail.com \\ Jurusan Sejarah Universitas Negeri Jakarta
}

\begin{abstract}
Abstrak
Perjuangan mempertahankan kemerdekaan merupakan salah satu fase penting dalam proses menjadi Indonesia, dimana narasi keberpihakan menunjukkan kontruksi peranan seseorang dalam kemerdekaan. Berdasarkan pendekatan etnis, kiprah orang atau suku betawi dalam masa kemerdekaan kurang mendapat porsi kajian yang maksimal dibandingkan dengan etnis lain, seperti Jawa, Sunda atau Minang. Dalam pembelajaran sejarah tidak banyak diuraikan jalannya pertempuran di Jakarta dan kiprah orang Jakarta atau betawi di dalamnya. Padahal, orang betawi memiliki peran yang tidak kalah pentingnya. Tulisan ini merupakan sebuah narasi mengenai kiprah orang betawi dalam revolusi kemerdekaan antara tahun 1945-1950 yang menunjukkan bahwa orang betawi memiliki peranan yang aktif dalam fase tersebut, baik orang betawi yang berasal dari lapisan ulama maupun kaum jago atau tentara. Secara khusus, ulama memiliki peranan yang dominan, karena masyarakat betawi tidak dapat dilepaskan dari ulama, dan ulama atau islam tidak bisa dilepaskan kehadirannya sebagai anti-tesis kolonialisme di tanah Jakarta.
\end{abstract}

Kata kunci: Guru merah putih, ulama, betawi, perjuangan kemerdekaan

\section{Pendahuluan}

Ketika kecil, peneliti yang berasal dari etnis betawi seringkali mendengar cerita dari ayahanda maupun nenek (saya memanggilnya dengan istilah "Nyai") mengenai kepahlawanan orang betawi. Biasanya, ayahanda menceritakan kepahlawanan Guru Mansur, ulama betawi dalam menentang penjajahan Jepang dan Belanda, sampai-sampai Masjid Jami Al Mansur juga menjadi korban serangan pasukan sekutu. Berbeda dengan ayahanda, Nyai lebih suka menceritakan kisah enjid atau kakek saya yakni Kyai Muhammad Nadjihun, dalam revolusi kemerdekaan. Enjid saya kebetulan berkawan akrab dengan Kyai Muhajirin Amsar Bekasi, Kyai Noer Ali Bekasi dan Kyai Ahmad Zayadi Klender, yang ketiganya dikenal sebagai pejuang kemerdekaan dari betawi. ${ }^{1}$ Enjid saya dilarang ikut oleh mereka bertiga, karena mereka ingin agar ada ulama yang tetap mengajar dan menyiapkan perbekalan. Berbagi strategi. Dari sinilah, saya merasakan sebuah jejak sejarah bahwa orang betawi memiliki andil yang besar dalam

\footnotetext{
${ }^{1}$ Tulisan ini sendiri tidak menguraikan peran Kyai Muhajirin dan Kyai Ahmad Zayadi, karena referensi yang memuat kiprah mereka dalam perjuangan kemerdekaan belum didapatkan. Dengan demikian cerita nenek saya lebih bersifat narasi lokal saja.
}

423 | Seminar Nasional Sejarah ke 4 Jurusan Pendidikan Sejarah Universitas Negeri Padang 
perjuangan menegakkan kemerdekaan dan Negara Kesatuan Republik Indonesia. Apalagi daerah yang orang betawi tempati yaitu Jakarta adalah pusat dari proses kolonialisme itu berlangsung.

Ketika memasuki "bangku sekolah" dan kemudian belajar sejarah, cerita heroisme orang betawi seakan lenyap tiada berbekas. Tidak ada satupun penjelasan dari guru sejarah mengenai kiprah betawi dalam kemerdekaan. Jikalau ada, yang disinggung adalah sebatas Muhammad Husni Thamrin dan Ismail Marzuki, tidak ada nama-nama yang diceritakan oleh ayahanda peneliti. Di bangku kuliah Jurusan Sejarah FIS-UNJ, cerita mengenai kepahlawanan orang betawi juga nyaris tidak ada.

Pada akhirnya, barulah saya menemukan sederet nama orang-orang betawi yang berjuang untuk kemerdekaan dalam monograf Robert Cribb yang berjudul "Gejolak Revolusi di Jakarta". 2 Dari buku itulah, saya mulai mengenali keberadaan Haji Darip yang legendaris maupun Moefreni Moekmin yang sangat berani dalam pertempuran di front timur jakarta atau blok klender-Cakung-Bekasi. Dalam monograf Cribb yang lain, tokoh ulama pejuang betawi seperti Haji Darip, ironisnya disebut dengan istilah gerombolan atau bandit yang menakutkan. ${ }^{3}$ Sebuah hal yang sangat mencederai perasaan orang betawi. Kajian Ali Anwar mengenai Kyai Noer Ali, merupakan karya yang proporsional dalam menjelaskan porsi keberadaan ulama betawi dalam perlawanan menentang penjajahan yang ditampilkan dalam wajah KH. Noer Ali. ${ }^{4}$

Namun demikian, untuk saya, sepenggal narasi Robert Cribb dan Ali Anwar, belum terasa cukup untuk menggambarkan kiprah orang betawi dalam gelanggang revolusi secara keseluruhan. Diperlukan sebuah kajian lain yang menguraikan profil-profil pejuang betawi secara komprehensif, sehingga dapat menggambarkan bahwa orang betawi yang berjuang tidaklah segelintir orang. Diperlukan sebuah upaya untuk menginventarisir orang betawi dalam revolusi, sehingga jejaknya dapat dinikmati oleh generasi betawi kemudian.

Setelah menunggu beberapa lama, ternyata harapan peneliti belum terjawabkan, sehingga pada akhirnya peneliti berkeinginan untuk menulis dan mengkaji sendiri perihal orang betawi di dalam revolusi. Tulisan ini merupakan sebuah ikhtiyar untuk menggambarkan peranan orang betawi dalam revolusi kemerdekaan Indonesia, khususnya peranan para ulama betawi, sehingga

2 Robert Cribb, Gejolak Revolusi di Jakarta, (Jakarta: Grafiti Press, 1990)

3 Robert Cribb, Para Jago dan Kaum Revolusioner Jakarta 1945-1949, (Depok: Komunitas Bambu, 2010), hal.67-68

4 Ali Anwar, KH. Noer Ali: Kemandirian Ulama Pejuang, (Bekasi: Yayasan At-Taqwa, 2006). Menarik juga disimak monograf Ahmad Fadli HS, Ulama Betawi, (Jakarta: Manhalun Nasyi'in Press, 2011).

424 | Seminar Nasional Sejarah ke 4 Jurusan Pendidikan Sejarah Universitas Negeri Padang 
orang betawi tidak melupakan bahwa mereka memiliki jejak investasi atas Indonesia sebagai sebuah Negara kesatuan yang terus dijaga dan dipertahankan.

\section{Jakarta Menjelang Revolusi}

Dengan penyerahan kekuasaan Belanda kepada Jepang atas wilayahHindia-Belanda pada 8 Maret 1942 di Kalijati, maka berakhirlah masa kekuasaan belanda di Indonesia. Sebagai penguasa baru, Jepang kemudian segera mengeluarkan larangan aktivitas perkumpulanperkumpulan bangsa Indonesia. Jepang juga membagi pulau jawa dan madura atas syuu (karesidenan), si (kabupaten), ken (kewedanaan), Gun Son (kecamatan), dan ku (desa). Selain itu ada juga yang namanya Tokubetsu Si yang statusnya sama dengan Syuu, tetapi karena unsur strategisnya, Tokubetsu Si ditetapkan oleh pembesar penguasa jepang. Dan Jakarta adalah satusatunya Tokubetsu Si di Pulau Jawa yang luasnya sama seperti wilayah Batavia dahulu.

Untuk memudahkan jalannya pemerintahan, wilayah Jakarta Tokubetsu Si dibagi menjadi tujuh kawasan atau siku yang meliputi: Penjaringan, Mangga Besar, Tanjung Priok, Tanah Abang, Gambir, Pasar Senen dan Jatinegara. Selanjutnya juga diadakan pembagian daerah Batavia Syuu, yang meliputi: Kerawang Ken yang terdiri atas Pangkalan Son dan Teluk Jambe Son, serta Jatinegara Ken yang terdiriatas: Jatinegara Gun (Cawang, Pondok Gede, Pasar Rebo, Pulo Gadung, Pasar Minggu, Bekasi Son (Bekasi dan Cilincing) dan Cikarang Gun (Cikarang, Sukatani dan Cabang Bungin). ${ }^{5}$

Setelah dibentuk tata kelola pembagian wilayah administratif, pemerintah Jepang menujuk para tokoh local untuk menjadi wedana atau pejabat birokrasi di kawasan tersebut. Kota Jakarta dipimpin oleh Bagindo Dahlan Abdullah dengan bantuan kepala kepolisian yang dipimpin oleh Mas Sutandoko.

Jepang kemudian melakukan usaha pendudukannya dengan membuat aturan yang menguatkan unsur Jepang, seperti pengibaran bendera jepang dalam upacara hari besar, pengajaran nyanyian lagu kebangsaan jepang Kimigayo serta penggunaan tahun jepang. Indoktrinasi kemudian semakin menguat lewat kebijakan politik yang dilakukan tidak hanya untuk kawasan jakarta, melainkan seluruh wilayah Hindia Belanda. Hal ini dapat dilihat dari pembentukan berbagai organisasi (Romusha, PETA, Fujinkai, Heiho dan lain-lain) serta gerakan

\footnotetext{
${ }^{5}$ Warmansyah $d k k$, Sejarah Revolusi Fisik Daerah DKI Jakarta, (Jakarta: Depdikbud, 1997), hal. 20-25 425 | Seminar Nasional Sejarah ke 4 Jurusan Pendidikan Sejarah Universitas Negeri Padang
} 
propaganda 3A (Jepang cahaya, pemimpin dan pelindung Asia). Kebijakan awal Jepang yang terlihat sangat bersahabat tentunya disambut baik oleh masyarakat Indonesia dan jakarta.

Namun demikian, dalam perkembangannya, "bulan madu" tersebut tidak berlangsung lama. Watak pemerintahan kolonial Jepang yang sesungguhnya mulai terlihat ketika banyak kebijakan pemerintahan Jepang yang menyengsarakan rakyat Indonesia. Kerja paksa lewat Romusha, kebijakan seikerei (membungkuk kearah Tokyo) serta bencana kelaparan yang tersebar di seluruh penjuru nusantara membuat rakyat semakin menderita di bawah pendudukan Jepang. Banyak yang beranggapan bahwa masa-masa pendudukan Jepang lebih menyengsarakan dibandingkan dengan masa-masa penjajahan belanda.

Umur kekuasaan Jepang di Indonesia sangat bergantung kepada situasi internasional perang dunia II. Ketika Hiroshima dan Nagasaki dibom oleh Amerika, menyusul kekalahan Italia dan Jerman, sekutu Jepang dalam Perang Dunia II, maka jepang pun kalah dalam Perang Dunia II. Indonesia yang dikuasai jepang, dengan demikian berada pada situasi tanpa penguasa atau vacum of power. Saat Jepang menyerah, Lord Mountbatten sebagai komandan pasukan sekutu di Asia Tenggara memerintahkan agar tawanan perang sekutu untuk tetap ditahanan mereka. Sekutu mengkhawatirkan para tawanan yang akan melakukan perlawanan, dan karenanya sekutu menyerahkan urusan keamanan untuk sementara masih dipegang oleh penguasa jepang yang kalah. Dengan ancaman pengadilan perang, sekutu memerintahkan Jepang bertanggung jawab atas stabilitas kawasan jajahan hingga sekutu datang. Namun demikian, orang belanda yang ditahan oleh jepang mengabaikan situasi ini. Mereka keluar penjara dan mengabaikan larangan sekutu, sehingga kelak mereka merusak rencana sekutu dan justru melahirkan revolusi sosial dan gelombang perlawanan diberbagai daerah Indonesia.

Ketika Proklamasi diumumkan Sukarno dan Hatta pada 17 Agustus 1945, orang-orang belanda tidak banyak bereaksi dan menganggapnya hanya sebatas lelucon. Namun kemudian, pasukan republic terbukti mampu mempertahankan kekuasaan dan menangkal tentara-tentara liar eks KNIL yang melindungi orang-orang belanda. Jepang sebagai pihak yang dipercayai menjaga stabilitas sebelum diserahkan kepada sekutu, juga terlihat bersimpati kepada perjuangan rakyat Indonesia. Mereka yang diperintahkan untuk menghancurkan gerakan perlawanan republik, memilih untuk diam saja dengan alasan agar tidak menimbulkan konflik horizontal dan kekacauan yang lebih besar. 


\section{Ulama Betawi dalam Revolusi}

Pada masyarakat Betawi, Islam adalah nafas kebudayaan dimana di dalamnya ulama memiliki kedudukan yang penting dan mendapatkan penghormatan lebih dibandingkan kedudukan atau status social lainnya. ${ }^{6}$ Masyarakat Jakarta menyebut ulama mereka dengan sebutan Guru, sebuah istilah yang menunjukkan bukan sekedar profesi atau pekerjaan, tetapi sebuah penghormatan atas kemampuan seseorang dalam bidang ilmu agama. Konsepsi Ustadz atau Kyai, baru muncul belakangan sesudah era kemerdekaan yang agaknya karena menasionalnya konsepsi keulamaan jawa.

Dalam Revolusi kemerdekaan, ulama atau para "Guru” Betawi memiliki peranan penting dalam keberpihakan kepada NKRI serta perjuangan bersenjata melawan kedatangan sekutu. Ketika proklamasi dibacakan, ulama betawi mendukungnya dan mengerahkan massa untuk menghadiri rapat-rapat akbar yang diadakah pemerintah republic. Ketika Jakarta berada di bawah kendali Inggris pada 1945-1946, banyak diantara badan perjuangan, termasuk di dalamnya ulama, yang melakukan gerilya atau menyingkir melakukan perlawanan ke luar Jakarta. ${ }^{7}$ Bahkan ulama juga dilibatkan dalam urusan ruhani untuk memberikan dukungan perjuangan berdasarkan dalil keagamaan. Tercatat dalam sejarah perjuangan Jakarta mengenai peristiwa Do'a Jum'at, yaitu anjuran pada akhir desember 1946, agar khotib jumat dikhutbah kedua membacakan do'a untuk tegak berdirinya Negara Kesatuan Republik Indonesia diseluruh masjid-masjid jami di penjuru Jakarta. $^{8}$ Hal ini menunjukkan bahwa ulama betawi menjadi ujung tombak dalam revolusi kemerdekaan.

\section{KH. Noer Ali ${ }^{9}$}

KH. Noer Ali Bin H. Anwar bin H. Layu lahir pada tahun 1914 di Desa Ujung Malang, Onderdistrik Babelan, Distrik Bekasi, Regentschap (Kabupaten) Meester Cornelis, Residensi Batavia, sebelum diganti menjadi Desa Ujung Harapan Bahagia, Kecamatan Babelan, Jawa Barat. Semasa kecil KH Noer Ali sudah memperlihatkan bakat kepemimpinan yang kuat, yakni mengorganisir permainan dan sifat tidak mau kalah. Noer Ali juga dikenal sebagai anak yang

\footnotetext{
${ }^{6}$ Menarik disimak karya Abdul Aziz berjudul islam dan Masyarakat Betawi, (Jakarta: Logos, 2002)

7 Susan Blackburn, Sejarah Jakarta 400 Tahun (Depok, Masup Jakarta, 2012), hal. 208

${ }^{8}$ Anwar, Rosihan. Kisah-kisah Jakarta Menjelang Revolusi, (Jakarta: Pustaka Jaya, 1985), hal. 114-115

${ }^{9}$ Bagian ini merujuk kepada monograf karya Ali Anwar, KH. Noer Ali: Kemandirian Ulama Pejuang,
} (Bekasi: Yayasan At-Taqwa, 2006). Peneliti juga mengandalkan informasi dari ibunda peneliti (Yati Nuryati) yang merupakan santri dari Kyai Noer Ali di Ujung Harapan.

427 | Seminar Nasional Sejarah ke 4 Jurusan Pendidikan Sejarah Universitas Negeri Padang 
pandai. Ia belajar kepada ayahandanya, Guru Maksum dan kemudian Guru Mughni di Ujung Malang. Kepada Guru Mughni, ia belajar alfiyah (tata bahasa Arab), al-Qur'ân, Tajwid, Nahwu, Tauhid, dan Fiqih. Noer Ali memiliki cita-cita untuk menjadi pemimpin agama dan membangun sebuah perkampungan surga. Dimana penduduknya beragama Islam dan menjalankan syariat Islam.

Setelah belajar agama kepada Guru Mughni, Noer Ali kemudian mondok ke Guru Marzuki di kampung Cipinang Muara, Klender. Disini KH. Noer Ali menempuh pendidikan tahap lanjutan setingkat Aliyah dengan mata pelajaran sebagaimana yang diberikan pada guru Mughni, tetapi materinya dikembangkan dengan aspek pemahaman yang lebih ditekankan, seperti pelajaran Tauhid, Tajwid, Nahwu, Sharaf dan Fiqih. Pada tahun 1933, karena dinilai cerdas dan mampu mengikuti pelajaran dengan baik, KH. Noer Ali diangkat menjadi badal, yang fungsinya menggantikan sang guru apabila ia sedang udzur (halangan). Di pondok guru Marzuki, KH. Noer Ali mempunyai banyak teman yang kelak akan menjadi sahabatnya dan ulama terkenal di bilangan Jakarta, Bogor, Tangerang, dan Bekasi, seperti KH. Abdullah Syafi'ie, KH. Abdurrachman Shadri, KH. Abu Bakar, KH. Mukhtar Thabrani, KH. Abdul Bakir Marzuki, KH. Hasbullah, KH. Zayadi dll. Sesuai dengan pesan gurunya, KH.Noer Ali kemudian melanjutkan belajar agama kepada Syeikh Ali al-Maliki di Makkah. Syeikh Ali al-Maliki adalah Syeikh yang mengajarkan berbagai macam cabang ilmu agama Islam, tapi ajarannya lebih dititikberatkan pada Hadits. Selain dengan Syeikh Ali al-Maliki, KH. Noer Ali pun menggali ilmu agama dari syeikh lain, terutama Syeikh Umar Hamdan, Syeikh Ahmad Fatoni, Syeikh Ibnul Arabi, Syeikh Muhammad Amin al-Quthbi, Syeikh Achyadi, Syeikh Abdul Zalil dan Syeikh Umar at-Turki. Kepada Syeikh Umar Hamdan yang berusia sekitar 70 tahun, KH.Noer Ali belajar Kutubussittah. Syeikh Ahmad Fatoni adalah Syeikh yang berasal dari Patani (Muangthai), berumur sekitar 40 tahun, yang memberikan pelajaran Fiqih dengan kitab Iqna sebagai acuannya. Melalui Syeikh Muhammad Amin al-Quthbi yang berusia 45 tahun, KH.Noer Ali belajar ilmu Nahwu, Qawafi (Sastra), dan Badi' (Mengarang). Selain itu Syeikh Quthbi pun mengajarkan ilmu Tauhid dan Mantiq (ilmu logika yang mengandung Falsafah Yunani) dengan kitab Asmuni sebagai acuannya.Sedangkan dari Syeikh Abdul Zalil diperoleh ilmu politik, Syeikh Umar at-Turki dan Syeikh Ibnul Arabi, diperoleh ilmu Hadits dan Ulumul Qur'an.

Berada jauh dengan tanah air tidak membuat KH.Noer Ali lupa dengan bangsanya. Melalui wesel dari orangtua dan surat kabar yang terbit di Saudi Arabia dan Hindia Belanda, 
KH. Noer Ali mengetahui situasi dan kondisi dunia dan tanah airnya. Adanya sarana organisasi seperti Perhimpunan Pelajar-Pelajar Indonesia (PPPI), Persatuan Talabah Indonesia (Pertindo), dan Perhimpunan Pelajar Indonesia-Malaya (Perindom), telah menggerakkan hati KH. Noer Ali untuk turut andil didalamnya. Pada beberapa kesempatan ia sempat berdialog dengan beberapa pelajar asal jepang, diantaranya adalah Muhammad Abdul Muniam Inada.

Betapapun pentingnya organisasi, KH.Noer Ali menyadari bahwa menuntut harus ilmu itu lebih diutamakan. Selain itu faktor yang membuat KH.Noer Ali tidak memasuki organisasi yang lebih besar adalah karena masih banyak teman-temannya yang kesulitan keuangan, dan lemahnya kemampuan intelektual dan pengalaman organisasi dari individu masing-masing teman-temannya.KH. Noer Ali pun sadar bahwa kekuatan bisa dibina dari yang kecil, dari yang bawah. Sebagai realisasinya, KH.Noer Ali dan beberapa temannya seperti KH.Hasan Basri membentuk organisasi Persatuan Pelajar Betawi (PPB), dengan KH.Noer Ali sebagai ketuanya. Ketika suasana mendekati perang dunia II ( akhir 1939 ), KH. Noer Ali yang sudah memiliki cukup ilmu memutuskan untuk kembali ke tanah air.Syeikh Ali al-Maliki yang melihat potensi keulamaan KH. Noer Ali, berpesan diakhir pertemuan: "Kalau kamu mau pulang, silahkan pulang. Tapi Ingat, jika bekerja jangan jadi penghulu (pegawai pemerintah). Kalau kamu mau mengajar, saya akan ridha dunia-akhirat”.

Kepulangan KH. Noer Ali ke kampung halamannya Ujung Malang pada awal Januari tahun 1940, telah menjadi duri dalam daging bagi tuan tanah dan pemerintah Hindia Belanda karena kemampuannya mengorganisir massa. KH. Noer Ali mendirikan pesantren, dan kemudian menggkoordinir pembangunan akses jalan secara besar-besaran antara kampung Ujung Malang, Teluk Pucung, dan Pondok Ungu yang dilakukan secara sukarela dan terselesaikan pada tahun 1941. Sebagai salah satu pemimpin agama terkemuka di betawi, namanya diusulkan masuk dalam daftar Shimubu (Kantor Urusan Agama), pada masa pendudukan Jepang (1942-1945). Namun KH.Noer Ali menyikapinya dengan sangat hati-hati, dan kemudian menolaknya. Untuk mempersiapkan diri bila sewaktu-waktu bangsa Indonesia harus bertempur secara fisik, KH.Noer Ali menyalurkan santrinya ke dalam Heiho (pembantu prajurit), Keibodan (barisan pembantu polisi) di Teluk Pucung, dan menyuruh salah seorang santrinya untuk mengikuti latihan kemiliteran Pembela Tanah Air (PETA).

Ketika Indonesia merdeka, ia terpilih sebagai Ketua Komite Nasional Indonesia Daerah (KNID) Cabang Babelan. Tanggal 19 September 1945 ketika diselenggarakan Rapat Raksasa di 
Lapang Ikada Jakarta, KH. Noer Ali mengerahkan massa untuk hadir. Dalam mempertahankan kemerdekaan, ia menjadi Ketua Laskar Rakyat Bekasi, selanjutnya menjadi Komandan Batalyon III Hisbullah Bekasi. Gelar kiai haji sendiri beliau dapatkan dari bung Tomo yang dalam pidatonya melalui pemancar Radio Surabaya atau Radio Pemberontaknya berkali-kali menyebut nama KH. Noer Ali, akhirnya gelar guru pun tergeser dan berganti dengan makna yang sama, Kiai Haji.

Ketika terjadi Agresi Militer Juli 1947 KH.Noer Ali menghadap Jenderal Oerip Soemohardjo di Yogyakarta. Ia diperintahkan untuk bergerilya di Jawa Barat dengan tidak menggunakan nama TNI. KH. Noer Ali pun kembali ke Jawa Barat dengan berjalan kaki dan mendirikan sekaligus menjadi Komandan Markas Pusat Hizbullah-Sabilillah (MPHS) Jakarta Raya di Karawang. Untuk menunjukkan bahwa pertahanan Indonesia masih eksis, dibeberapa tempat MPHS melakukan perang urat syaraf (psy-wars). KH Noer Ali memerintahkan pasukannya bersama masyarakat di Tanjung Karekok, Rawa Gede dan Karawang untuk membuat bendera merah-putih ukuran kecil yang terbuat dari kertas. Ribuan bendera tersebut lalu ditancapkan di setiap pohon dan rumah penduduk dengan tujuan membangkitkan moral rakyat bahwa ditengah-tengah kekuasaan Belanda masih ada pasukan Indonesia yang terus melakukan perlawanan. Aksi herois tersebut membuat Belanda terperangah dan mengira pemasangan bendera merah-putih tersebut dilakukan oleh TNI, Belanda langsung mencari Mayor Lukas Kustaryo, karena tidak ditemukan Belanda marah dan membantai sekitar empat ratus orang warga sekitar Rawa Gede.

Pembantaian yang terkenal dalam laporan De Exceseen Nota Belanda tersebut memang berhasil menghancurkan kekuatan rakyat, tetapi berhasil memberikan pesan bahwa disekitar Karawang, Cikampek, Bekasi dan Jakarta masih ada kekuatan Indonesia yang aktif melawan belanda. Apalagi, setelah peristiwa tersebut, Belanda dianggap melakukan kejahatan perang karena telah melakukan pembunuhan keji terhadap penduduk yang tidak bedosa.

Pada tanggal 29 November 1945 terjadi pertempuran sengit antara pasukan KH Noer Ali dengan Sekutu di Pondok Ungu. Pasukan yang sebelumnya telah telah dibekali dengan motivasi lewat praktek puasa, doa hizbun nasr, ratib al-haddad, wirid, shalat tasbih, shalat hajat, dan shalat witir, kemudian lupa dengan pesan KH. Noer Ali agar tidak sombong dan angkuh. Melihat gelagat yang tidak baik, KH. Noer Ali menginstruksikan seluruh pasukannya untuk mundur. Sebagian yang masih bertahan akhirnya menjadi korban di pertempuran Sasak Kapuk. 
Kecintaan terhadap bidang pendidikan telah membuat KH.Noer Ali berinisiatif untuk membentuk Lembaga Pendidikan Islam (LPI) bersama KH.Rojiun, yang salah satu programnya adalah mendirikan Sekolah Rakyat Islam di Jakarta dan Jawa Barat. Di Ujung Malang, KH Noer Ali kembali mengaktifkan pesantrennya dengan SRI sebagai lembaga pendidikan pertama. Pada bulan Juli 1949 KH.Noer Ali diminta oleh Wakil Residen Jakarta Muhammad Moe'min untuk menjadi Bupati Jatinegara.Teringat pesan gurunya Syeikh Ali al-Maliki agar tidak menjadi pegawai pemerintah, maka KH. Noer Ali pun menolak dengan halus tawaran tersebut.

Paska perang kemerdekaan perjuangan KH.Noer Ali terus berlanjut dalam bidang politik, pendidikan, dan social. Pada tanggal 19 April 1950 KH. Noer Ali ditunjuk sebagai Ketua Masyumi Cabang Jatinegara. Peran Politik KH Noer Ali cukup besar dalam perjuangan pergerakan Republik Indonesia terutama untuk wilayah Bekasi. KH.Noer Ali juga tercatat sebagai salah seorang yang membidani lahirnya kabupaten bekasi yang sebelumnya bernama kabupaten Jatinegara. KH. Noer Ali juga membentuk organisasi sosial yang diberi nama Pembangunan Pemeliharaan dan Pertolongan Islam (P3) yang kedepannya akan berganti nama menjadi Yayasan Attaqwa. Yayasan P3 adalah induk dari pendidikan SRI, pesantren, dan kebutuhan ummat Islam lainnya. Bersama H. Suko Martono, pejabat Pemerintah Daerah Bekasi, dan tokoh Islam di Bekasi, KH. Noer Ali turut serta membentuk Yayasan Nurul Islam, yang salah satu programnya adalah membangun gedung Islamic Centre Bekasi, yang ide pembangunannya berasal dari KH. Noer Ali. Pada 29 Januari 1992, KH.Noer Ali wafat, dipanggil Sang Khaliq di rumahnya, di tengah-tengah kompleks Pondok Pesantren Attaqwa Putri yang dirintisnya sejak muda.

\section{Guru Mansur}

Salah satu tokoh betawi yang aktif dalam kegiatan perjuangan kemerdekaan adalah Guru Mansur yang bertempat tinggal di kawasan Jembatan Lima. Berdasarkan informasi brosur di Masjid al Mansuriyah, Guru Mansur lahir pada 31 Desember 1878 di kawasan Kampung Sawah, Jembatan Lima, Tambora, Jakarta Barat. ${ }^{10}$

Nama lengkapnya adalah Muhammad Mansur bin Imam Abdul Hamid bin Imam Muhammad Damiri bin Imam Habib bin Abdul Mukhit alias Pangeran Tjokrodjojo (Cakrajaya)

${ }^{10}$ Booklet mengenai Guru Mansur, diterbitkan oleh pengurus Masjid al Mansyuriyah, 2018.

431 | Seminar Nasional Sejarah ke 4 Jurusan Pendidikan Sejarah Universitas Negeri Padang 
Tumenggung Mataram. ${ }^{11}$ Silsilah ini menunjukkan asalnya dari kawasan Mataram, dimana Pangeran Cakrajaya disebutkan sebagai seorang pejuang melawan VOC diera abad ke-18. Nasab Pangeran Cakrajaya sendiri kemudian berujung kepada Sunan Giri bin Maulana Ishaq. Dengan demikian, silsilah nasabnya menunjukkan latar belakang Guru Mansur sebagai penerus perjuangan para ulama terdahulu yang anti kolonialisme.

Gelar Guru yang melekat pada nama Guru Mansur menunjukkan kepada konsepsi ulama yang mempunyai keahlian dalam suatu disiplin ilmu tertentu, mempunyai otoritas untuk mengeluarkan fatwa dan memiliki kemampuan mengajar dan menulis kitab ${ }^{12}$. Seorang Guru biasanya menghabiskan seluruh waktuya di masjidnya saja, yang lazimnya di dekat masjidnya itu berdiri kompleks madrasah. Guru tidak keluar dari lingkungannya karena orang-oranglah yang mendatanginya. Kriteria berikutnya adalah Mualim. Seorang mualaim itu mempunyai otoritas untuk mengajarkan kitab tetapi belum belum memiliki otoritas mengeluarkan fatwa. Seorang mualim mendatangi kelompok-kelompok pengajian untuk mengajarkan kitab. Kriteria ketiga adalah ustadz.Ustadz mengakarkan ilmu pengetahuan dasar agama termasuk membaca alQuran.

Guru Mansur dari Kampung Sawah, Jembatan Lima, hidup satu generasi dengan Guru Mugni dari kampung Kuningan. Kedua tokoh ini pada zamannya disebut orang Betawi sebagai paku Jakarta. Generasi Guru Mansur merupakan pelanjut ulama Betawi generasi Guru Mujtaba dari kampung Mester. Perjalanan keilmuan Guru Mansur cukup panjang. Pada tahun 1894, Guru Mansur berangkat ke Mekkah ketika berusia 16 tahun bersama ibunya. Beliau tinggal di Mekkah selama 4 tahun beliau berguru kepada Tuan Guru Umar Sumbawa. Beliau juga berguru kepada Guru Mukhtar, Guru Muhyiddin, Syekh Muhammad Hayyath, Sayyid Muhammad Hamid, Syekh Said Yamani, Umar al Hadromy dan Syekh Ali al-Mukri.

Setelah mukim selama 4 tahun di Mekkah, Guru Mansur kemudian kembali ke tanah air dengan terlebih dahulu singgah di Aden, Benggala, Kalkuta, Burma, India, Malaya dan

11 Dokumen keluarga mengenai catatan nasab keturunan Pangeran Cakrajaya. Kebetulan peneliti juga bagian dari catatan pohon keluarga tersebut. Catatan yang dimiliki peneliti ini dibuat sekitar pada tahun 1970-an agar tidak terjadi "mati obor" atau hilang ingatan terhadap silsilah keluarga.

12 Dimasa hidupnya, Guru Mansur telah menulis 19 buku berbahasa Arab yaitu:Sullamunnarain, Khulasatuljadawil, kaifiyatul amal ijtima, khusuf wal kusuf, Mizanul I'tidal, Washilatuth thullab, Jadwal dawairul falakiyah, Majmu' arba rasail fi mas 'alatil hilal, Rub'ul mujayyab ,Mukhtasar iktima'unnairain, Tajkirotun nafi'ah fisihati 'amalissaum wal fitr, Tudhul adillah fissihatissaum wal fitr, Jadwal faraid, Al lu'lu ulmankhum fi khulasoh mabahist sittah ulum,I'rabul jurumiyah annafi' lil mubtadi,Silsilatissanat fiddin wa ittisoluha sayyidul musalin, Tashriful abwallimatan bina, Jidwal kiblat, Jidwal au kutussolah, serta Tathbiq amalul ijtima' wal khusuh wal kusuf 
Singapura. Sekembalinya di kampung halamannya, Guru Mansur mulai membantu ayahnya mengajar di madrasah Kampung Sawah.Sejak tahun 1907, beliau mengajar di Jamiatul Khair, Kampung Tenabang. Di sinilah beliau mulai berkawan dan menjalin hubungan intelektual-politik dengan tokoh-tokoh Islam seperti Syekh Ahmad Syurkati dan KH Ahmad Dahlan yang juga anggota perkumpulan Jamiatul Khair.

Pada 1915, saat menjadi pengulu daerah Penjaringan, Guru Mansur menjadikan Falaq sebagai patokan penetapan awal Ramadan dan Idul Fitri. Semasa hidupnya, Guru Mansur berhubungan sangat baik dengan tokoh-tokoh Islam.Guru Mansur dekat kalangan Nahdlatul Ulama (NU) lewat komunikasi dengan KH Hasyim Asyari, sedangkan dari kalangan Muhammadiyah Guru Mansur dikenal dekat dengan pendiri Muhammadiyah KH Ahmad Dahlan.Kemudian Guru Mansur juga dekat dengan tokoh seperti M. Nassir, KH Mas Mansur, HOS Tjokroaminoto dan sebagainya.

Ketika NU masih dipimpin KH Hasyim Asyari, Guru Mansur pernah menjabat sebagai Rais Syuriah NU DKI Jakarta serta mengikuti muktamar ke-3 NU di Surabaya pada 1928. Setelah pulang dari Muktamar NU, Guru Mansur mendirikan Madrasah yang diberi nama Nahdlatul Ulama dan pada 1951 berganti nama menjadi Madrasah Chairiyah Mansuriyah hingga sekarang. Sebagai ulama terkenal, tentunya Guru Mansur sudah banyak menciptakan keturunan serta murid-murid yang pandai ilmu agama. Satu diantara dari keturunan Guru Mansur yang menjadi ulama kondang yakni Ustaz Yusuf Mansur.

Pergaulannya dengan tokoh-tokoh islam menjadikan figur Guru Mansur sebagai figur yang keras dalam menentang kebijakan yang dinilai merugikan umat islam dan kolonialisme. Pada tahun 1925 tatkala masjid Cikini di Jalan Raden Saleh hendak dibongkar dan pembongkaran ini disetujui oleh Raad Agama (pengadilan agama), Guru Mansur melancarkan protes keras sehingga akhirnya pembongkaran masjid tersebut dibatalkan.

Guru Mansur adalah penganjur dan pendukung kemerdekaan Indonesia.Beliau menyerukan agar bangsa Indonesia memasang atau mengibarkan bendera merah putih. Beliau menyerukan persatuan umat dengan slogannya yang terkenal, rempuk! Yang artinya musyawarah (perkataan ini kemungkinan besar maksudnya sama dengan rembuk). Beliau menuntut agar hari Jum'at dinyatakan sebagai hari libur bagi umat Islam.

Pada tahun 1948 tatkala kota Jakarta berada dalam kekuasaan de facto Belanda, Guru Mansur sering berurusan dengan Hoofd Bureau kepolisian di Gambir karena beliau memasang 
bendera merah putih di menara masjid Kampung Sawah. Meskipun di bawah ancaman bedil NICA/Belanda, Guru Mansur tetap mempertahankan Sang Saka Merah Putih yang berkibar di menara masjid. Akibatnya menara mesjid ditembaki oleh pasukan belanda, yang sisa-sisa bekas pelurunya masih menjadi saksi bisu di menara masjid al Mansuriyah.

Guru Mansur pernah dibujuk kaki tangan Belanda agar mengubah sikapnya yang konfrontatif terhadap Belanda dan sebaliknya diminta agar menurut saja apa yang dikehendaki Belanda seraya disodorkan setumpuk uang kepadanya, namun bujukan itu ditolak mentahmentah oleh Guru Mansur. Dengan suara lantang, Guru Mansur bersikeras berpendapat bahwa Islam tidak mau ditindas, karena beliau tidak ingin membela atau mendukung belanda yang dianggap sebagai pelaku kebatilan.

Guru Mansur wafat pada hari Jum'at 12 Mei 1967 dan dimakamkan di area Masjid Al Mansur. Sebagai penghormatan atas jasanya, pemerintah DKI Jakarta pada tahun 1969 mengabadikan nama KH Muhammad Mansur sebagai nama jalan yang membentang diantara Jalan Pangeran Tubagus Angke hingga Jalan KH Zainul Arifin di Jakarta Barat.

\section{Guru Amin}

Kiai Raden Haji Muhammad Amin atau Guru Amin (1901-1965) adalah salah seorang ulama betawi yang juga terlibat dalam perjuangan kemerdekaan. Nasabnya yang berujung kepada Pangeran Sanghiang Jatinegara Kaum, menunjukkan rekam jejak leluhurnya sebagai bangsawan Jayakarta yang terus menerus melakukan perlawanan sejak kedatangan belanda ke tanah betawi.

Guru Amin muda menimba ilmu agama dari berbagai ulama betawi, seperti: Guru Ending, Guru Marzuki, Guru Mansur, Guru Abdurrahim Kuningan serta Syekh Mukhtar Atharid di Makkah. Sejak usia 12 tahun, ia sudah menggantikan ayahnya mengajarkan kitab fathul mu'in di masjid kalibata. Guru Amin berkawan akrab dengan Kyai Noer Ali Ujung Harapan, yang kemungkinan mempengaruhi aktifitas Guru Amin kemudian dalam perjuangan kemerdekaan dan Partai Masyumi. Dalam hal organisasi social, Guru Amin dikenal sebagai tokoh Nahdlatul Ulama.

Di masa revolusi kemerdekaan, Guru Amin adalah salah-satu ulama yang ikut berjuang melawan belanda. Ia memimpin santrinya dalam pertempuran melawan belanda di Kalibata, sehingga Guru Amin menjadi salah-satu target penangkapan tentara belanda. Bahkan beberapa 
kali rumah Guru Amin dan keluarga Guru Amin didatangi belanda, sehingga Guru Amin akhirnya melarikan diri ke Cikampek dengan menyamar sebagai tukang beras. Di Cikampek, bersama para santrinya ia juga memimpin pertempuran melawan belanda di beberapa front.

Ketika Guru Amin kembali ke rumahnya di kalibata pada 1948, ternyata isi rumahnya sudah berantakan karena didatangi dan digeledah paksa oleh belanda yang mencari keberadaan Guru Amin. Semua kitab yang disusun dalam tiga lemari berantakan, dan tidak bisa digunakan lagi. Namun demikian, karena situasi Jakarta yang masuk ke dalam kawasan zona damai, membuat Guru Amin tidak lagi menjadi target penangkapan. Namun demikian, karena setiap hari rumah Guru Amin selalu didatangi oleh para santrinya, maka pihak belanda curiga bahwa Guru Amin akan memobilisasi massa untuk melawan belanda. Alhasil kemudian, aktifitas Guru Amin dibatasi belanda, dimana beliau hanya diperbolehkan keluar rumah hanya untuk mengajar di madrasahnya di Pesantren Unwanul Huda. Guru Amin tidak diperkenankan ke tempat lain, hinga kemudian belanda angkat kaki setelah penyerahan kedaulatan $1950 .{ }^{13}$

Setelah belanda angkat kaki, Guru Amin berkhikmad di organisasi Nahdlatul Ulama dan Partai Masyumi. Guru Amin adalah orang yang berhasil mengorganisir keberadaan penghulu agama di Jakarta, bekasi, tangerang dan karawang atas perintah menteri agama, KH. Masykur. Setelah berhasil menyelesaikan tugas itu, Guru Amin ditunjuk sebagai kepala para penghulu atau KUA kawasan tersebut.

Guru Amin wafat pada 31 Agustus 1965 dan kemudian dimakamkan di komplek pesantrennya. Semula, ia akan dimakamkan di Taman Makam Pahlawan Kalibata, karena ia termasuk veteran perang kemerdekaan. Namun, akhirnya diputuskan agar hal itu tidak dilakukan, karena kelak murid-muridnya akan sulit jika ingin berziarah ke makam Guru Amin.

\section{KH. Rahmatullah Shidiq}

Rahmatullah Shidiq Bin Muhammad Shiddiq bin H. Daud bin ismail dilahirkan pada 12 November 1923 dari pasangan H. Muhammad Shidiq yang lebih dikenal dengan Guru Shidiq dengan Hj. Rohimah. Sejak kecil Rahmatullah sudah dididik bekerja keras karena pada zaman penjajahan Belanda menuntut anak di bawah umur harus bekerja membantu orang tua mencan nafkah. Rahmatullah menjajakan kue keliling kampung dan setelah itu belajar al-Qur'an di rumah kakeknya, H. Daud bin Ismail yang dikenal dengan Guru Daud.

13 Ahmad Fadli HS, Ulama Betawi, Jakarta: Manhalun Nasyi'in Press, 2011, hal 120-126

435 | Seminar Nasional Sejarah ke 4 Jurusan Pendidikan Sejarah Universitas Negeri Padang 
Selain belajar agama kepada ayalmya, Rahmatullah juga menempuh pendidikan di sekolah HES (Holladech Engels Scool) di Kebayoran Lama dan di Madrasah Unwanul Falah, Habib Ali Kwitang. Rahmatullah juga belajar agama kepada kakek dari ibunya, Guru Thohir yang pernah belajar di Makkah beberapa tahun.Ketika di Makkah, Guru Thohir bertemu dengan Guru Kholid yang kemudian kembali ke tanah aIr dan menetap di Gondangdia Jakarta Pusat.

Setelah beranjak dewasa, Rahmatullah terus menimba ilmu kepada ulama-ulama terkemuka, seperti belajar ilmu falak, fara'id dan lain-lain kepada Tuan Guru Usman Perak dari Melayu, belajar bahasa Arab dan ilmu tafsir kepada Prof. H. Abdullah bin Nuh, belajar ilmu tajwid dan qiroat kepada KH. Nahrawi Al-Hafidz. Kepada ulama yang sebaya, KH.Rahmatullah Shidiq sering berdiskusi dan saling tukar pikiran tentang bidangnya masing-masing, antara lain kepada KH. Tb. Mansur Ma'mun, KH. Armin dari Serang Banten dan KH.Abdul Hannan Sa'id Sawah Besar selanjutnya bersama KH.Tb. Mansur Makmun dan KH.Nahrawi mendirikan Jam'iyatul Quro wal Huffadz dan pemah menjadi dewan hakim MTQ Nasional di Jakarta pada tahun 1972.

Dalam perjalanan hidupnya, KH.Rahmatullah Shidiq berdakwah dan mengajar di Masjid Jami AlFalah Kampung Baru Jakarta Barat yang telah diresmikan oleh H. Muhammad Natsir (Ketua Masyumi) pada tahun 1955.Di masjid inilah KH.Rahmatullah Shidiq mengajar tafsir dan mengajar Juga di beberapa masjid lainnya sehingga menjadi guru tetap di bidang tafsir di Masjid Istiqlal dan Perguruan As-Syafi'iyah.Kemudian la diangkat menjadi Imam di Masjid Baiturrahim di lingkungan Istana. ${ }^{14}$

Rahmatullah Shidiq di samping sebagai pengajar Juga seorang pejuang dan politisi.KH.Rahmatullah Shidiq bertemu dengan KH.Noer Ali ketika membantu Tentara Keamanan Rakyat (TKR) dalam mempelancar distribusi keperluan logistic, khususnya di wilayah Rengas Dengklok Karawang, Bekasi dan Jakarta. Oleh KH. Nur Ali, KH. Rahmatullah diperkenalkan dengan H. Muhammad Natsir selaku Ketua Umum Masyumi. Melalui Partai Masyumi, KH. Rahmatullah Shidiq menjadi anggota DPR hasil pemilu 1955. Di DPR, ia seangkatan dengan H. Abdul Salim, H. Ghazali Sahlan, Mr. Kasman Singodimejo dan Muhammad Rum.

\footnotetext{
${ }^{14}$ Keterangan ini didapat dari wawancara dengan nenek peneliti, Hj. Suhaibah binti Junaidi pada tahun 1999, kebetulan keluarga peneliti masih berhubungan kekerabatan dengan keluarga KH. Rahmatullah Shidiq.

436 | Seminar Nasional Sejarah ke 4 Jurusan Pendidikan Sejarah Universitas Negeri Padang
} 
Kiprahnya sebagai pejuang di tanah betawi adalah sebagai pengatur dan penyedia logistic bagi pasukan TKR di kawasan Rengas Dengklok, Bekasi dan Jakarta. Tentunya hal ini bukan sebuah perkara mudah dizaman penuh ancaman dan kekerasan, karena apabila tertangkap oleh pihak belanda, maka hukuman yang berat sudah menanti di depan mata. Berkat perjuangan beliaulah, yang mengamankan logistic bagi para pejuang, maka perjuangan melawan kolonialisme tetap berlangsung dan mengantarkan kemerdekaan Indonesia secara de fakto pada 1945. Setelah penyerahan kedaulatan, beliau aktif di Nahdlatul Ulama dan Partai Masyumi. Lewat Masyumi, beliau menjadi anggota DPR dalam Pemilu 1955. Setelah itu, beliau mendirikan madrasah al Falah yang masih eksis hingga sekarang. Madrasah itu menjadi pusat atau markas Banser Nu dalam penumpasan PKI ditahun 1965.

\section{KH. Hasbiyallah}

Nama Lengkapnya KH. Hasbiyallah bin H. Mu`allim Ghayar bin H. Abdurrahim bin Ali Basa bin Jamaluddin. Mengenai tanggal kelahirannya, tidak ada keterangan yang pasti.Begitu pula dengan tahun kelahirannya, Ada data yang menyatakan tahun 1913 namun ada pula data yang menyatakan tahun 1914.Ia merupakan anak kedua dari delapan bersaudara dari pasangan Mu`allim Ghayar (KH. Anwar) dan Hj. Mamnin binti Ja`man bin Supariman. Ia wafat pada tanggal 24 Rabiul Tsani 1403 H, bertepatan dengan tanggal 18 Februari 1982 M pada usia sekitar 78 tahun. Ia dimakamkan di kompleks pemakaman keluarga yang berada tepat di depan masjid Al-Makmur, Klender, Jakarta Timur. ${ }^{15}$

Sejak kecil, ia didik oleh bapaknya sendiri. Namun karena kesibukan bapaknya, ia kemudian diserahkan kepada Guru Marzuqi Cipinang Muara untuk meneruskan pendidikannya, memperdalam kitab-kitab kuning sampai Guru Marzuqi wafat pada tahun 1934. Selanjutnya ia menempuh pendidikan di Pondok Pesantren Buntet, Cirebon yang diasuh ulama kharismatik, KH. Abbas. Kepada KH. Abbas, ia mempelajari qiraat sab`ah. Selain itu, ia juga mengaji kepada Guru Muhammad Thohir Cipinang Muara (menantu Guru Marzuki), Guru Khalid Gondangdia, Guru Madjid Pekojan, dan Guru Barah. Kemudian, ia menyusul kakaknya KH. Hasbullah untuk meneruskan pendidikannya ke Makkah.Di Makkah, ia mengaji kepada ulama terkemuka di antaranya adalah Syekh Ali Al-Maliki, Sayyid Alwi bin Abbas Al-Maliki, Syekh Muhammad Habibullah As-Sanqithi, Syekh Muhammad Amin Kutbi, Syekh Umar Hamdan, Syekh Hasan

\footnotetext{
${ }^{15}$ Rakhmad Zailani Kiki, Genealogi Intelektual Ulama Betawi, Jakarta Islamic Centre, 2011)
} 437 | Seminar Nasional Sejarah ke 4 Jurusan Pendidikan Sejarah Universitas Negeri Padang 
Al-Masysyath, Syekh Ali Al-Yamani, Syekh Zakariya Bila, Syekh Ahmad Fathoni, dan Syekh Umar At-Turki.

Hasbiyallah merupakan sosok yang sangat peduli dengan dunia pendidikan.Ia mendirikan majelis taklim dan perguruan Al-Wathoniyah yang sekarang telah memiliki 61 cabang yang didirikan oleh murid-muridnya. Ia juga memiliki karya tulis yang berjudul Risalah Kaifiyah Sembahyang Tarawih dan Sholat Al-`Aidain. Karena keluasan dan kedalaman ilmunya, ia kerap menjadi tempat ulama meminta pendapat dan mentashihkan karya tulisnya. Seperti KH. Abdurrahman Nawi (pendiri dan pimpinan Perguruan Al-Awwabin) yang meminta kepada KH.Hasbiyallah untuk mentashhih risalah karangannya yang berjudul Manasik Haji.

Sebagai seorang ulama, ia tidak hanya disibukkan membaca kitab, tetapi juga merupakan sosok yang peduli kepada persoalan masyarakat dan bangsanya. Saat terjadi agresi militer Belanda Kedua, bersama dengan dua rekannya yang lain, H. Darip dan KH. Achmad Mursyidi, ia turut berjuang di front terdepan dan dikenal sebagai "tiga serangkai" dari Klender.

Semasa kemerdekaan, Hasbiyallah berjuang mempertahankan Indonesia dari Belanda dan Jepang.Kiai bergabung dengan ulama terkemuka dengan pasukan gerilya dan hizbullah.Kiai bergerilya ke hutan dengan para laskar mengusir pasukan Belanda.Kiai berdoa minta kepada Allah agar diberikan kekuatan para laskar menang dalam peperangan.Maka dengan kekuasan dan barokahnya para lascar menang dan mampu menguasai daerah Klender, Jakarta Timur.Nama Hasbiyallah kini termasuk pejuang yang diberi pahlawan nasional oleh Pemerintah Provinsi DKI, karena keikutsertaan dalam melawan Belanda. Menurut penuturan anaknya yang bernama Siti Hasanah, KH Hasbiyallah merupakan ulama besar di masanya dan ikut memperjuangkan kemerdekaan RI. Dia benteng Jakarta dari para musuh Belanda dan Jepang kala itu, sehingga hidupnya banyak dihabiskan untuk membela Negara. ${ }^{16}$

\section{KH. Achmad Mursyidi}

Salah seorang ulama sekaligus pejuang dari Betawi yang terkenal selain KH.Noer Ali di antaranya adalah KH. Achmad Mursyidi. Ia lahir di Kampung Bulak, Klender, Jakarta Timur

\footnotetext{
${ }^{16}$ https://www.viva.co.id/berita/metro/639604-kiai-ini-usir-belanda-hanya-dengan-sorban, diakses pada 21 Januari 2018 Pukul 12.04 WIB.

438 | Seminar Nasional Sejarah ke 4 Jurusan Pendidikan Sejarah Universitas Negeri Padang
} 
pada tanggal 15 November 1915 dari pasangan H. Maisin dan $\mathrm{Hj}$. Fatimah dan wafat pada tanggal 9 April 2003, di usia 88 tahun. $^{17}$

Pendidikannya dimulai di Sekolah Rakyat (SR) di Pulo Gadung, Jakarta Timur, dari tahun 1926 sampai tahun 1930. Kemudian ia mengaji kepada Guru Marzuki Cipinang Muara dari tahun 1930 sampai tahun 1934. Kemudian mengaji kepada Ajengan Toha di Plered, Purwakarta, Jawa Barat dari tahun 1934 sampai tahun 1935. Setahun setelah selesai mengaji kepada Ajengan Toha, di usia yang ke-21 tahun, ia mendirikan Madrasah Raudhatul Athfal di Kampungnya, Kampung Bulak, Klender. Di tahun yang sama pula, 1936, ia berumah tangga dengan $\mathrm{Hj}$, Asyiah bin Mua`llim H. Gayar. Di tahun ini pula ia meneruskan belajarnya dengan mengaji kepada KH. A. Thohir Jam`an dan juga mertuanya, Mu`allim Ghayar, bapak dari KH. Hasbiyallah dan KH.Hasbullah.

Jiwa kepahlawanan dan kepemimpinan KH. Achmad Mursyidi mulai kelihatan ketika pada tahun 1945 ia aktif di Menteng 31, markas Angkatan Pemuda Indonesia (API) dan mendirikan Barisan Rakyat (BARA) di Kampung Bulak, Klender. Dari tahun 1945 sampai tahun 1949, ia terlibat aktif dalam perang mengusir agresi Belanda dan sekutunya. Saat itu, ia menjadi komandan perjuangan rakyat yang mempunyai kewenangan untuk membentuk pemerintahan di tingkat kecamatan atau kewedanan. Kepahlawanannya dikenal bersama dengan dua rekannya, $\mathrm{H}$. Darip dan KH.Hasbiyallah, sebagai tiga serangkai dari Klender.

Saat itu agresi Belanda semakin menjadi sehingga Klender tidak bisa dipertahankan, baik melalui perundingan diplomasi yang dilakukan H. Hasbullah maupun kemampuan persenjataan.Akhirnya garis perbatasan mundur ke wilayah Cakung dan Klender terpaksa ditinggalkan.Tentara penjajah tumpah di Klender dan menjadikan halaman Masjid Al-Makmur sebagai markas. Dari pada menjadi markas penjajah lebih baik Klender musnah menjadi lautan api. Dengan modal beberapa botol bensin yang diberi sumbu, kira-kira pukul dua siang, aksi membumi hanguskan dilakukan. Selama lebih kurang tiga jam Klender menjadi laupan api.

Usia peperangan, pada tahun 1949, ia melanjutkan perjuangan melalui pendidikan dengan mendirikan madrasah Lembaga Pendidikan Islam Al-Falah (LPA Al-Falah). Ia juga aktif di organisasi Nahdlatul Ulama (NU). Selain pejuang, ia dikenal sebagai politisi ulung. Karena karir politiknya, pada tahun 1957, ia dilantik menjadi anggota DPR hasil pemilu tahun 1955 menggantikan KH. Ahmad Djunaidi. Kemudian pada tahun 1959, ia dilantik kembali menjadi

${ }^{17}$ Kiki Rakhmad Zailani, Genealogi Intelektual Ulama Betawi, (Jakarta Islamic Centre, 2011) 439 | Seminar Nasional Sejarah ke 4 Jurusan Pendidikan Sejarah Universitas Negeri Padang 
anggota DPR dalam rangka kembali ke UUD 1945, setelah Dekrit Presiden dikelaurkan pada tanggal 5 Juliu 1959. Pada tahun 1960, kembali ia dilantik menjadi anggota DPR-GR.

Selepas dari DPR-GR, ia kembali menuntut ilmu dengan mengaji kepada Habib Ali bin Husein Al-Atas (Habib Ali Bungur) dari tahun 1968 sampai wafatnya Habib Ali Bungur pada tahun 1976. Namun, di sela-sela masa mengajinya, ia kembali masuk ke Senayan dengan menjadi anggota MPR dari Partai NU. Selain itu, tanpa melupakan dakwah, ia turut mendirikan Majelis Takilm Pusat Umat Islam At-Tahiriyah. Pada tahun 1977, kembali menjadi anggota MPR dari PPP karena politik Orde Baru membuat partai NU melakukan fusi ke PPP yang terjadi pada tahun 1973. Pada tahun 1978, ia dilantik menjadi anggota DPA-RI menggantikan KH. Idham Cholid. Saat itu, KH.Idham Cholid diangkat menjadi Ketua DPA-RI. Pada tahun 1982, ia kembali menjadi anggota legislatif, anggota DPR/MPR RI dari daerah pemilihan DKI Jakarta. Pada tahun 1985, dipercaya untuk menjadi Ketua Umum MUI DKI Jakarta menggantikan KH. Abdullah Syafi i. Dikarenakan ia adalah kader PPP dari fraksi PPP, maka ia diminta mundur dari jabatannya. Pada tahun 1987, kembali ia dilantik menjadi anggota DPR/MPR RI dari daerah pemilihan Jawa Timur. Dalam sidang paripurna DPR RI, ia sempat menjadi pimpinan sementara sidang paripurna. Pada tahun 1992, kembali dilantik menjadi anggota MPR RI sampai kemudian pensiun pada tahun 1997. Karena tidak lagi menjadi politisi, pada tahun 1999, ia dipercaya kembali menjadi Ketua Umum MUI DKI Jakarta sampai akhir hayatnya.

\section{Muhammad Arif atau Haji Darip}

H. Muhammad Arif bin Kurdin atau biasa dipanggil H. Darip dilahirkan di Klender pada tahun 1886. Ia tidak menempuh pendidikan formal membaca dan menulis. Pelajaran membaca dan menulis huruf latin justru diperolehnya saat dipenjara dan belajar dari temannya. Dalam belajar agama, tidak diketahui kepada siapa H. Darip belajar agama akan tetapi ada kemungkinan ia belajar agama langsung kepada ayahnya. ${ }^{18}$

Pada tahun 1914 ia pergi haji ke Makkah dan langsung menetap di sana untuk memperdalam ilmu agama hingga kurang lebih dua tahun setengah (1916). Pulang dari Mekah, H. Darip mengawali perjuangannya dengan berdakwah di sebuah mushalla kecil, yang kini menjadi Masjid Al-Makmur yang cukup megah di Klender dan berjuang bersama para ulama

\footnotetext{
${ }^{18}$ Ahmad Fadli HS, Ulama Betawi: Studi Tentang Jaringan Ulama Betawi dan Kontribusinya Terhadap Perkembangan Islam Abad ke-19 dan 20, (Jakarta: Manhalun Nasyi'in Press, 2011), hal 229-237. Bagian Haji Darip ini juga berdasarkan naskah ketikan yang berjudul "Haji Darip: Pejuang dari Betawi yang Terlupakan". Naskah ketikan tanpa keterangan siapa yang mengarangnya ini merupakan dokumen keluarga yang kemungkinan berasal dari hasil wawancara sebuah majalah pada tahun 1980-an.
} 
lain, yakni KH Mursyidi dan KH Hasbullah. Selain dikenal sebagai da'i, ia juga seorang yang memiliki ilmu main pukulan (ilmu silat) yang lihai. Ia adalah seorang tokoh yang disegani masyarakat, daerah kekuasaannya mencakup Klender, Pulogadung, Jatinegara hingga sampai Bekasi.

Kebenciannya kepada kolonialisme sudah tertanam sejak lama, kemungkinan kebencian itu menyemai ketika ia menempuh studi di mekkah. Selain sebagai tempat orang naik haji dan belajar agama islam, mekkah juga dikenal sebagai pusat jaringan nusantara dalam melawan kolonialisme belanda. Sangat wajar, sepulang dari Mekkah, pada 1923 ia memimpin sebuat pemogokan buruh kereta api di Jakarta. Namun, karena sedikitnya massa dan kurangnya dukungan dari kaum nasionalis, gerakan ini segera dipadamkan, dan Jakarta kembali aman.

Pada saat terjadi revolusi fisik melawan Jepang dan Belanda, H. Darip membentuk BARA (Barisan Rakyat). Ia mengumpulkan para tokoh, pemuda dan jagoan yang tersebar di Klender dan sekitarnya. Di antara mereka yang ikut bergabung adalah H. Hasbullah (Kakak dari KH. Hasbiyallah) dan KH. Mursyidi. Mereka terlibat dalam pertempuran di beberapa front di kota Jakarta. H. Darip sendiri saat itu dijuluki"Panglima Perang dari Klender". Sebuah brosur dari Angkatan 45 DKI tanggal 17 Agustus 1985-empat tahun setelah Haji Darip meninggal dunia-menyebutkan, H. Darip pada zaman penjajahan Belanda (sebelum perang dunia kedua), berjuang bersama Soekarno bergerak di bawah tanah, terutama di Cilincing, Tanjung Priok, Jakarta Utara.

Ketika pendudukan Jepang, menyaksikan kekejaman pasukan Dai Nippon ini, H. Darip memimpin masyarakat di Klender dan menghimpun para jawara, narapidana dan napi Rutan Cipinang untuk melakukan perlawanan terhadap Jepang. Sewaktu dia masih memimpin pergerakan dari Klender, banyak para pemimpin yang datang bahkan menginap di kediamannya, di antaranya Soekarni, tokoh Murba, Kamaludin, Syamsuddin orang Padang, dan Pandu Kartawiguna. Mereka menginap di rumah H. Darip dan menyatakan kepadanya bahwa sebentar lagi Indonesia akan merdeka dan mereka membicarakan pengusiran orang Jepang.

Anak buah H. Darip yang tergabung dalam BARA dimandikan oleh H. Darip kemudian diisi badannya dengan ilmu kebal lalu dicoba dengan dibacok badannya dengan golok. Setelah dirasa memiliki ilmu kebal maka pasukan BARA diperbolehkan untuk berjuang mengusir Jepang. H. Darip memerintahkan anak buahnya untuk menyerbu dan mengusir tentara Jepang di Pangkalan Jati, Pondok Gede, Cipinang Cempedak, sepanjang Kali Cipinang dan lain-lain. Anak 
buah H. Darip bahkan sampai membunuh tentara Jepang. Hal tersebut dilakukan oleh anak buah H. Darip karena jika tentara Jepang tidak dibunuh maka anak buah H. Darip yang terbunuh karena tentara Jepang mempunyai senjata api sedang anak buah H. Darip hanya mempunyai kekuatan fisik dan golok saja. Beberapa sumur di Klender dan sekitarnya tidak ada yang mau minum airnya karena penuh dengan bangkai tentara Jepang, begitupula dengan sungai Sunter yang dipenuhi dengan mayat tentara Jepang.

Setelah berhasil mengerahkan rakyat yang dihimpun dan dipimpinnya untuk menghabiskan tentara Jepang yang bertugas di pinggiran, maka H. Darip menyadari bahwa kekuatan rakyat tidak akan berarti jika tidak dilengkapi dengan peralatan senjata, logistik dan persediaan makanan. Kira-kira seminggu sebelum Indonesia memproklamirkan kemerdekaan, H. Darip mendatangi Camat Klender dan meminta segala pakaian rakyat yang akan dibagikan jangan dikeluarkan sebelum saatnya tiba dan menunggu komando darinya.

H. Darip juga mendatangi kantor polisi yang masih di bawah kekuasaan Jepang. Ia meminta supaya senjata-senjata yang ada di kantor polisi jangan diserahkan kepada Jepang, melainkan harus diserahkan kepada rakyat nanti. Lalu H. Darip menyuruh komandan polisi membuat pernyataan dan membubuhkan tanda tangannya untuk menyerahkan senjata kepada rakyat. Kemudian H. Darip pergi ke Seksi Tujuh. Ia bertemu dengan Darmatin dan Juhra anak Banten dan Sukahar dan meminta kepada mereka agar persenjataan yang ada di sana diserahkan kepada rakyat. Kemudian H. Darip menuju penjara Cipinang. Direkturnya diberi tahu hal yang sama dengan apa yang dikatakan pada Camat, Kepala polisi maupun Komandan Seksi VII. Pada saatnya pula nanti H. Darip meminta agar para tahanan dilepaskan. Ia juga datang ke Seksi V dan melakukan hal yang sama.

Hari Proklamasi makin dekat dan suasana politik semakin memanas, tetapi Haji Darip telah mempersiapkan anak buahnya. Haji Darip juga mendatangi gudang-gudang beras di Klender untuk memblokir beras agar tidak keluar dari Klender. Maka jadilah Klender wilayah pertahanan yang merupakan gudang makanan dan persenjataan ala kadarnya.

H. Darip mempersiapkan hal tersebut di atas setelah mendapat informasi dari Soekarni bahwa Indonesia sebentar lagi akan merdeka. Informasi itu diperoleh ketika terjadi serangan bom atom di Hiroshima pada 6 Agustus 1945 dan Nagasaki pada 9 Agustus 1945 oleh Amerika Serikat atas perintah Presiden Amerika Serikat Harry S. Truman. Setelah pengeboman tersebut maka pada 15 Agustus, Jepang mengumumkan bahwa Jepang menyerah tanpa syarat kepada 
Sekutu. Berita ini diketahui oleh kalangan pemuda bangsa Indonesia melalui berita siaran radio BBC (British Broadcasting Corporation) London. Pada saat yang sama Soekarno dan Hatta baru kembali ke tanah air memenuhi panggilan Panglima Mandala Asia Tenggara, Marsekal Terauchi di Saigon, Vietnam.

Saat kembali ke tanah air, Soekarno ditemui para pemuda untuk membicarakan kemerdekaan Indonesia. Kemudian pada tanggal 16 Agustus 1945 pukul 04.00 WIB, Soekarno dan Hatta "diculik" dan dibawa ke Rengasdengklok, Karawang oleh para pemuda di antaranya Soekarni, Chaerul Saleh dan lain-lain. Dalam peristiwa Rengasdengklok itu, H. Darip menjadi saksi hidup ketika para pemuda mendesak Soekarno Hatta agar mempercepat proklamasi kemerdekaan Republik Indonesia. Kemudian Soekarno Hatta ditempatkan di suatu rumah yang tidak layak di pinggir kali. Lalu H. Darip meminta kepada Soekarni dan kawankawannya agar Soekarno Hatta di tempatkan di rumah yang layak karena Soekarno Hatta adalah calon pemimpin yang harus dihormati. Atas permintaan H. Darip maka Soekarni dan kawankawan menempatkan Soekarno Hatta di rumah perkampungan milik warga Tionghoa,Djiaw Kie Siong.

Pada waktu itu Soekarno dan Hatta menginginkan agar proklamasi dilakukan melalui PPKI (Panitia Persiapan Kemerdekaan Indonesia) sementara golongan pemuda menginginkan agar proklamasi dilakukan secepatnya tanpa melalui PPKI yang dianggap sebagai badan buatan Jepang. Selain itu, hal tersebut dilakukan agar Soekarno dan Hatta tidak terpengaruh oleh Jepang.Para golongan pemuda khawatir apabila kemerdekaan yang sebenarnya merupakan hasil dari perjuangan bangsa Indonesia, menjadi seolah-olah merupakan pemberian dari Jepang.

Setelah melalui perundingan yang panjang akhirnya disepakati bahwa proklamasi kemerdekaan dilaksanakan pada 17 Agustus di Jakarta kemudian bendera Merah Putih dikibarkan para pejuang di Rengasdengklok pada Rabu tanggal 16 Agustus, sebagai persiapan untuk proklamasi kemerdekaan Indonesia. Pada akhirnya, tepatnya hari Jumat, 17 Agustus 1945 atau bertepatan dengan 09 Ramadlan $1364 \mathrm{H}$, Soekarno dan Muhammad Hatta memproklamirkan kemerdekaan Republik Indonesia. Proklamasi kemerdekaan tersebut disambut suka cita oleh seluruh rakyat Indonesia, tak ketinggalan rakyat yang berada di Klender dan sekitarnya. Setelah proklamasi kemerdekaan, Soekarno berkunjung ke Klender dan memimpin 
rapat akbar di sana serta meminta rakyat Klender ikut membantu mempertahankan kemerdekaan Indonesia.

Selanjutnya H. Darip memerintahkan rumah-rumah di Klender menaikkan bendera merah putih. Pabrik-pabrik di Klender, Cipinang, Jatinegara dan lain-lain diperintahkan mengganti bendera Jepang dengan merah putih. H. Darip juga meminta agar pabrik tidak mengeluarkan beras kecuali untuk makan laskar rakyat. Setelah berhasil menghimpun senjata, makanan dan pakaian, H. Darip memerintahkan anak buahnya untuk menjaga ketat wilayah Klender agar tidak dimasuki tentara Jepang atau mata-mata Jepang.

Setelah Jepang menyerah dan kembali ke negerinya, Belanda dan tentara sekutu berusaha kembali menjajah Bangsa Indonesia. H. Darip bersama pasukan BARA bersiap-siap untuk mempertahankan kemerdekaan Indonesia sebagaimana yang diamanatkan oleh Soekarno saat rapat akbar di Klender.

Pada suatu penyerangan, Klender berhasil diduduki Belanda dan sekutu sehingga $\mathrm{H}$. Darip dan pasukan BARA hijrah ke beberapa tempat seperti Tambun, Cikarang, Lemah Abang, Bekasi, Cikampek, Karawang hingga ke Purwakarta dan membentuk BPRI (Barisan Pejuang Rakyat Indonesia) Jakarta Raya. Dari tempat persembunyiannya-dengan pangkat Letnan Kolonel Tituler - ia bermarkas di Purwakarta dan menyusun strategi melawan NICA Belanda.

Suatu ketika benteng pertahanan di Purwakarta diserang oleh Belanda melalui hujan bom dan peluru dari udara dan darat sehingga $H$. Darip dan pasukannya harus mengungsi ke hutan. Perjalanan ke hutan sangat memprihatinkan, terlebih di antara 4 (empat) isteri H. Darip ada yang sedang hamil dan ada yang mempunyai bayi yang masih kecil. Mereka harus turun naik bukit, menyebrang sungai dan menahan lapar dan dahaga. Jika rasa lapar dan dahaga tidak tertahankan mereka singgah ke rumah penduduk setempat untuk meminta makanan dan minuman. Di kemudian hari untuk keselamatan anak dan isteri-isterinya, H. Darip mengirimkan mereka ke Klender dan berpesan agar tidak memberitahukan kepada siapapun tentang posisi H. Darip dan pasukannya.

Pada saat memasuki bulan puasa, H. Darip dan pasukannya tetap berpuasa dan berjuang melawan Belanda. Mereka dari Parakan Lima menuju hutan Cempaka, hutan Bendul, Kembang Kuning dan Cibatu. Di hutan Cempaka H. Darip menghimpun kekuatan dan mengatur strategi untuk menyerang musuh. Pertahanan Belanda di Purwakarta kerapkali dibuat panik oleh serangan mendadak yang tidak terduga di malam hari atau menjelang subuh hingga suatu ketika 
Jayusman, anak buah H. Darip yang berasal dari Banten tertangkap. Ia ditembak tetapi tidak mempan dan akhirnya ia tewas setelah dipulir kepalanya.

Belanda berusaha keras untuk menangkap H. Darip akan tetapi usaha itu sia-sia. Bahkan Belanda menjanjikan hadiah besar bagi orang yang bisa menangkap H. Darip. Pada akhirnya Belanda mengirim mata-mata untuk bergabung dan menjadi anak buah H. Darip. Tersebutlah Jami dan Sarosa yang menjebak dan membujuk H. Darip agar pergi ke Jogjakarta untuk kembali dekat dengan Soekarno. Sejak Januari 1946 Ibukota memang pindah dari Jakarta ke Jogjakarta.H. Darip kemudian berhasil ditangkap pasukan Belanda, tangannya diikat erat dengan kabel listrik dan dibawa memakai mobil Jeep. Dari Sadang H. Darip dibawa ke Jakarta kemudian dimasukkan ke sel Polisi I Kebayoran selama tiga hari lalu dipindah ke Ancol. Dalam kondisi tetap diikat dengan kabel listrik, H. Darip disiksa dengan gagang senapan dan dipukul bertubitubi sampai akhirnya H. Darip dijebloskan ke tahanan Glodok, Jakarta Kota (kini merupakan bagian dari pertokoan Harco) pada tahun 1948.Berita tertangkapnya H. Darip sampai ke anak buahnya. Mereka sangat marah ternyata pimpinannya tertangkap karena dijebak dan dikhianati oleh Jami. Kemudian anak buahnya mencari-cari Jami hingga akhirnya Jami ditangkap dan tewas dibunuh oleh anak buah H. Darip yang setia.

Pada akhir tahun 1949 H. Darip menulis surat kepada Soekarno agar ia dibebaskan dari penjara. Konon surat tersebut diterima oleh Fatmawati, istri Soekarno di Istana Negara. Tetapi Soekarno tidak bisa membebaskan H. Darip. Setelah penyerahan kedaulatan pada akhir Desember 1949, H. Darip akhirnya dibebaskan dari penjara. Para anak buahnya yang hampir 100 orang menyambut H. Darip di luar penjara dan membawa ke rumah Ghozali di Kebon Jahe kemudian ke Klender. Rumahnya di Klender sudah habis dibakar oleh Belanda saat ia di penjara. Lalu bersama-sama anak buahnya dan rakyat Klender secara gotong royong membuat rumah sederhana untuk H. Darip.Pada Mei atau Juni 1950 H. Darip dipanggil Soekarno ke Istana Cipanas. Ia dijemput oleh Letnan Ishaq Latief. Dalam pertemuan tersebut dihadiri oleh Menteri Pertahanan Hamengkubuwono. Soekarno menyambut dan memeluk H. Darip sambil menangis. Soekarno lalu menjelaskan surat H. Darip yang dikirimkan untuknya. Soekarno merasa yakin bahwa H. Darip akan bebas dan tidak akan mati di penjara.

Pada tahun 1950 ketika keamanan Jakarta belum sepenuhnya stabil, foto H. Darip terjual habis. Masyarakat Jakarta, khususnya Klender dan terutama keturunan Cina akan merasa aman 
jika rumahnya terpampang foto $\mathrm{H}$. Darip. Para pencoleng dan gerombolan penjahat tidak akan menggangu rumah atau toko yang terpampang foto $\mathrm{H}$. Darip.

H. Darip adalah rakyat biasa yang kemudian memimpin rakyat untuk melawan dan mengusir penjajah. Ia memiliki wibawa sehingga bisa menggerakan api semangat perlawanan terhadap penjajah. Ia juga berjuang tanpa pamrih sehingga ia tidak memperdulikan gelar veteran dan pahlawan. Di akhir masa hidupnya, ia menghabiskan waktu untuk berdakwah di Klender dan sekitarnya untuk mengamalkan ilmu yang ia dapat saat belajar di Makkah.H. Darip meninggal di Jakarta pada 13 Juni 1981 dan dimakamkan di Pemakaman Wakaf Ar-Rahman Jalan Tanah Koja II, Jatinegara Kaum, Pulogadung Jakarta Timur bersebelahan dengan makam salah satu istrinya, Hj. Hamidah.

\section{Simpulan}

Setelah mendapatkan narasi mengenai tujuh orang ulama betawi dalam revolusi kemerdekaan, kita menemukan sebuah benang merah bahwa ulama di Jakarta atau betawi merupakan ujung tombak dari perjuangan kemerdekaan. Ulama memiliki peran dengan menyediakan dalih dalil untuk melawan, mengorganisasikan rakyat untuk bergerak serta ikut langsung memimpin perjuangan kemerdekaan. Aktivitas ini menunjukkan adanya persesuaian antara pikiran dengan tindakan.

Tentusaja, hal ini menjadi sebuah catatan menarik apabila kita mengurutnya berdasarkan geneanologi perlawanan di tanah betawi, mengingat para ulama tersebut memiliki garis geneanologi dengan para pejuang di era sebelumnya. Guru Mansur misalnya adalah keturunan dari Pangeran Cakrajaya yang merupakan tokoh perlawananan terhadap belanda di betawi pada abad 18-19, sedangkan Guru Amin berasal dari trah Pangeran Jayakarta, penguasa lama Jakarta sebelum ditaklukkan belanda diabad 17. Dengan demikian, ada warisan semangat yang dipertahankan atau ditularkan antara generasi, sehingga bara perlawanan terus hadir dan menemukan momentumnya pada masa perang revolusi kemerdekaan.

Setting sejarah yang demikianlah yang kemudian memberikan ruang islam secara cultural bergerak secara berbeda di tanah betawi. Faham fiqih yang cenderung mengadopsi pola ahlusunnah waljama'ah dengan amaliyah yang memiliki tradisi mirip dengan Nahdlatul Ulama di Jawa, kemudian bertemu dengan semangat islam formal yang dapat diradikalisasi untuk kepentingan tertentu yang lebih mirip dengan Masyumi. Namun demikian, wajah ulama betawi 
tidak berubah, tetap menjadi "Guru Merah Putih" yaitu ulama yang setia kepada ajaran islam ahlusunnah waljamaah dan Negara Kesatuan Republik Indonesia. Dan orang betawi pada hari ini harus menyadari bahwa mereka memiliki saham atas kemerdekaan Indonesia, sehingga sangat penting untuk merawat kebanggan tersebut dan menjaganya sebagai warisan kebangsaan bersama.

\section{DAFTAR PUSTAKA}

Anwar, Ali. KH. Noer Ali: Kemandirian Ulama Pejuang, Bekasi: Yayasan At-Taqwa, 2006

Anwar, Rosihan. Kisah-kisah Jakarta Menjelang Revolusi, Jakarta: Pustaka Jaya, 1985

Aziz, Abdul. Islam dan Masyarakat Betawi, Jakarta: Logos, 2002

Blackburn, Susan. Sejarah Jakarta 400 Tahun Depok, Masup Jakarta, 2012

Booklet mengenai Guru Manyur, diterbitkan oleh pengurus Masjid al Mansuriyah, 2018

Cribb, Robert. Gejolak Revolusi di Jakarta, Jakarta: Grafiti Press, 1990

Cribb, Robert. Para Jago dan Kaum Revolusioner Jakarta 1945-1949, Depok: Komunitas Bambu, 2010

Dokumen keluarga mengenai catatan nasab keturunan Pangeran Cakrajaya.

Fadli HS, Ahmad. Ulama Betawi: Studi Tentang Jaringan Ulama Betawi dan Kontribusinya Terhadap Perkembangan Islam Abad ke-19 dan 20, Jakarta: Manhalun Nasyi' in Press, 2011 https://www.viva.co.id/berita/metro/639604-kiai-ini-usir-belanda-hanya-dengan-sorban, diakses pada 21 Januari 2018 Pukul 12.04 WIB.

Koleksi keluarga Haji Darip yang berjudul Haji Darip: Pejuang dari Betawi yang Terlupakan". TT

Rakhmad Zailani, Kiki. Genealogi Intelektual Ulama Betawi, Jakarta Islamic Centre, 2011

Warmansyah, dkk . Sejarah Revolusi Fisik Daerah DKI Jakarta, Jakarta: Depdikbud, 1997

\section{Informan}

Yati Nuryati, santri dari Kyai Noer Ali di Ujung Harapan 18 Agustus 2017

Hj. Suhaibah binti Junaidi pada tahun 1999, keluarga peneliti yang masih berhubungan kekerabatan dengan keluarga KH. Rahmatullah Shidiq. 